\title{
A Research on Mathematics Education Studies Published between 2009-2014 in Turkey
}

\section{Lütfi INCIKABI ${ }^{*}$, Mehmet Koray SERIN ${ }^{2}$, Samet KORKMAZ ${ }^{3}$, Semahat iNCIKABI ${ }^{4}$}

${ }^{1,2}$ Kastamonu University, Faculty of Education, Turkey

${ }^{3,4}$ Kastamonu University, Faculty of Education PhD Student, Turkey

\begin{tabular}{l} 
ARTICLE INFO \\
\hline Article History: \\
Received \\
09.09.2016 \\
Received in revised \\
form 09.03.2017 \\
Accepted \\
17.03.2017 \\
Available online \\
30.06.2017
\end{tabular}

\begin{abstract}
The purpose of this study is to analyze the content of the studies focused on mathematics education and published between 2009-2014 in faculty of education journals and in ulakbim.gov.tr, and to determine the trends of related studies. Within this scope, 284 articles in the selected journals have been reached and classified. In this process a paper classification form, developed by Sozbilir, Kutu and Yasar (2012) was revised and used for the analysis. Each publication has been subjected to content analysis through this form and eight components which provide descriptive information for the identification of the paper, sub-disciplinary area and learning domain of the paper, subject (title) of the paper, methods employed in the study, data collection tools used, sampling and sample sizes, authors and data analysis methods. As a result of the analysis of the obtained data, the articles are not generally focused on the learning areas clearly and that the subject of teacher training is predominantly performed as non-experimental studies. In addition to these, undergraduate students mostly preferred as a target sample. Also it was determined that the achievement tests and interview forms come to the fore as data collection tools.
\end{abstract}

(C) 2017 AUJES. All rights reserved

Keywords:

Mathematics education, research, article, content analysis.

\section{Extended Abstract}

\section{Purpose}

Periodicals studies analyzing offers data to researchers, academics and other people who intending to article study. Thus the areas which need to focus are becoming more apparent. Completed studies offer different work proposals about mathematics education researches and argue that the more comprehensive studies need for mathematics education. In this study a content analysis was conducted examining the articles published in the faculty of education journals and journals registered to ulakbim.gov.tr between 2009-2014 years. Reached articles have been examined under titles which named sub-disciplinary area and

\footnotetext{
${ }^{*}$ Corresponding author's address: Kastamonu University, Faculty of Education, Department of Elementary Mathematics Education, Kastamonu

e-mail: lincikabi@kastamonu.edu.tr
} 
learning domain of the paper, subject (title) of the paper, methods employed in the study, data collection tools used, sampling and sample sizes, authors and data analysis methods.

\section{Method}

In this study which realized towards mathematics education researches case study, one of the qualitative research designs, was used. Collection of data performed by the document analysis method. In this context reached 284 article located in the specified journals and studies have been classified. In this process a paper classification form, developed by Sozbilir, Kutu and Yasar (2012) was revised and used for research in mathematics education. Each publication has been subjected to content analysis through this form and eight components which provide descriptive information for the identification of the paper, sub-disciplinary area and learning domain of the paper, subject (title) of the paper, methods employed in the study, data collection tools used, sampling and sample sizes, authors and data analysis methods. Data were analyzed by content analysis method in line with qualitative research design.

\section{Results}

First of all, we examined the studies that analyzed in scope of research and its distribution of learning areas. According to this, it seems that about half of studies (43\%) not point out any learning area of mathematics. Considering the articles dealing with the mathematics learning areas, geometry and measurement (16\%) with numbers and operations learning (14\%) areas taking a place near the top. Although no significant difference, teacher training (22\%) and curriculum, measurement and evaluation (18\%) subjects are preferred in mathematics education studies. Non-experimental methods are utilized in more than half of the studies (57\%). Studies having an interactive nature were at the second place. At related years; the studies that utilizing any experimental, mixed and not interactive methods are staying at low rate. Achievement test (22\%), interview forms (21\%) and questionnaire (\% 17) are most preferred data collection tools in the studies. Undergraduate (35\%) and secondary (25\%) school students are often taking a place as a sample in the studies of mathematics education. Teachers (15\%), high school students (12\%), and primary school students (7\%) respectively following this. 31-100 (26\%) and 101$300(26 \%)$ sample sizes are most preferred sample sizes in the studies. At data analyzing of the studies, quantitative (40\%) and qualitative (45\%) methods mostly preferred but mixed methods (8\%) used at low rate. Authors' studies (38\%) who working at same university, are remarkable among the studies of the mathematics education. Researchers' studies who working at different university are composing the $26 \%$ of all studies. Studies revealed by single author are composing the $20 \%$ of all studies. Authors $(67,3 \%)$ are mostly expert at 
mathematics education field and they don't want to work with experts who working at different fields. After this, researchers who expert at field of educational sciences are performing mathematics education studies as a single or with experts $(7,4 \%)$ at field of educational sciences.

\section{Discussion and Conclusion}

According to research findings, the least targeted learning areas are probability and data analysis. Moreover, it has been observed that researches are mostly carried out in the field of teacher training. This may be due to the fact that the authors give priority to research on candidate teachers because they mostly work at universities. In addition, the topics addressed least by the subject areas are mathematics history, philosophy, epistemology, the nature of mathematics, and non-formal learning. In the distribution of research methods, it is seen that the general tendency is to carry out non-experimental researches. These results are in parallel with both domestic and foreign literature. On the other hand, quantitative and paradigm based methods are used more in the studies in our country while qualitative and mixed patterns are given more importance in foreign literature.

According to the results of the current research, studies were mostly carried out by not only one author but also by several authors. When we look at the distribution of the authors, it is seen that the studies put forward by the authors of the same university are predominant. The results of the research show that the vast majority of authors in the mathematics education researches involving more than one author are engaged only in the field of mathematics education.

This research was carried out in order to determine the current situation and general tendency of mathematics education researches in Turkey. It is believed this investigation is also very important to have guidance to the people who desirable to perform research in this area. As stated above aforementioned study gives information to the researchers about the areas needs to focus on giving place to main titles such as learning area, subject area. Moreover, it may contribute on increasing the quality of mathematics education research to be performed in the future by emphasis overlooked or missed points under the method title. 


\title{
Türkiye' de 2009-2014 Yılları Arasında Yayımlanan Matematik
} Eğitimi Çalışmaları Üzerine Bir Araştırma

\author{
Lütfi iNCIKABI ${ }^{1^{*}}$, Mehmet Koray SERIN ${ }^{2}$, Samet KORKMAZ ${ }^{3}$, Semahat \\ INCIKABI ${ }^{4}$
}

${ }^{1,2}$ Kastamonu Üniversitesi Eğitim Fakültesi

${ }^{3,4}$ Kastamonu Üniversitesi Eğitim Fakültesi Doktora Öğrencisi

MAKALE BİLGI

Makale Tarihçesi: Alındı 09.09.2016

Düzeltilmiş hali

alındı 09.03.2017

Kabul edildi

17.03.2017

Çevrimiçi yayınlandı 30.06.2017

\section{ÖZET}

$\mathrm{Bu}$ çalışmanın amacı, eğitim fakültesi dergilerinde ve ulakbim.gov.tr adresinde yer alan dergilerde 2009-2014 yılları arasında yayımlanan matematik eğitimi odaklı çalışmaların içerik analizinin gerçekleştirilmesi ve bu paralelde söz konusu çalışmaların eğilimlerinin belirlenmesidir. Bu kapsamda belirlenen dergilerde yer alan 284 makaleye ulaşılarak çalışmalar tasnif edilmiştir. Bu süreçte Sözbilir, Kutu ve Yaşar (2012) tarafından geliştirilen "Yayın Sınıflama Formu" çalışmanın amacına göre gözden geçirilerek öğrenme alanı, konu alanı, araştırma yöntemi, veri toplama araçları, örneklem, veri analiz yöntemleri, yazarlar ve disiplin alanı şeklinde sekiz bölümden oluşturulmuş ve analiz sürecinde kullanılmıştır. Elde edilen verilerin analizi sonucunda ulaşılan bazı sonuçlara göre makalelerin genellikle öğrenme alanlarına net bir şekilde odaklanmadıkları, öğretmen yetiştirme konu alanı baskın olmak üzere daha çok deneysel olmayan çalışmalar şeklinde gerçekleştirildikleri görülmüştür. Bunlara ilaveten hedef kitle olarak daha çok lisans öğrencilerinin tercih edildiği, veri toplama aracı olarak başarı testleri ve görüşme formlarının ön plana çıktığı belirlenmiştir.

(c) 2017 AUJES. Tüm hakları saklıdır

Anahtar Kelimeler:

Matematik eğitimi, araştırma, makale, içerik analizi

\section{Giriş}

Matematik, insan yeteneklerinin ortaya çıkarılmasında, yönlendirilmesinde, sistemli ve mantıklı bir düşünce alışkanlığının kazandırılmasında amaçtır. Aynı zamanda insanın hayatının her noktasında karşısına çıkan bir araçıı (Aydın, 2003; Gün ve Çavuş Erdem, 2014). Matematik günümüzde tıp, ekonomi, yönetim, sosyal ve siyasal bilimler gibi uygulama alanlarında söz sahibi olarak çağdaş bilime hizmet etmekte ve bununla birlikte tüm bilimler için vazgeçilmez bir kaynak olarak kullanımaktadır (Aksu, 2008). Sözü edilen bu geniş uygulama alanı varlığı öğretim faaliyetleri üzerinde de etkisini göstererek matematik eğitimi alanının giderek söz sahibi olmasını sağlamış; eğitim programlarında matematiğe ayrılan yer, verilen

\footnotetext{
*Sorumlu yazarın adresi: Kastamonu Üniversitesi, Eğitim Fakültesi, İlköğretim Matematik Öğretmenliği Anabilim Dalı, Kastamonu, Türkiye

e-posta: lincikabi@kastamonu.edu.tr
} 
önem belirgin bir şekilde artış göstermiştir (Çoban, 2002). Son yıllarda matematik, fen ve teknoloji alanlarında yaşanan gelişmeler, ülkelerin bu alanlara yönelim ve araştırmalarını artırmış ve hazırladıkları eğitim politikalarında fen ve matematik eğitimine daha fazla odaklanmalarına sebep olmuştur (Çiltaş, Güler ve Sözbilir, 2012). Matematik eğitiminde yaşanan güçlükler, programdaki hızlı değişimler, eğitimcilerin ve öğrencilerin beklentileri farklı akademik çalışmalara konu olmuştur. Bu çalışmaların her biri literatüre farklı bir bakış açısıyla katkı sağlamıştır (Arık ve Türkmen, 2009). Dünyada, fen bilimleri ve matematik eğitimi araştırmalarında 20. yüzyılın ikinci yarısında gözlenen hareketlenme, Türkiye'de bu yüzyılın son on yılı ve 2000'li yıllarda ivmeli bir artışla kendini göstermiştir (Tatar ve Tatar, 2008).

Bilim ve teknolojideki gelişmeler bilginin ulaşılabilirliğini artırırken bunun bir sonucu olarak bilimsel araştırmalarda da artış gözlenmiştir. Bilimsel dergiler yapılan bu çalışmaların aktarılması ve bilimin ilerlemesi açısından büyük önem teşkil etmektedir. Süreli yayınların incelenmesi ve eleştirisinin yapılması literatürümüzde çok az başvurulan bir yöntemdir (Arık ve Türkmen, 2009). Akademik dergilerde yayınlanan makalelerin sistemli olarak değerlendirilmesi, matematik eğitimi araştırmasının şimdiki durumunu görmek ve gelecekteki eğilimlerinin farkında olmak için faydalı bulunmaktadır (Ulutaş ve Ubuz, 2008). Genelde eğitim özelde matematik eğitimi araştırmalarının belirli aralıklarla incelenip düzenlenmesi, bu yolla alandaki eğilimlerin belirlenmesi, araştırmacılar için önemli bir yol göstericidir. Günümüzde matematik eğitimi alanında değişik eğitim kademelerinde ve konu alanlarında birbirinden bağımsız çok sayıda çalışma yapılmaktadır. Söz konusu çalışmalar üzerinden araştırma eğilimleri ve araştırmaların sonuçlarına dayalı değerlendirmeler yapılarak alana ve araştırmacılara önemli katkılar sağlanabilir (Cohen, Manion ve Morrison, 2007; Selçuk, Palancı, Kandemir, Dündar, 2014).

Alan eğitiminin gelişmesi açısından yapılan araştırmalar önemli bir role sahiptir (Apaydın, 2009). Ülkemizde de belirli periyotlarla farklı araştırmacılar tarafından matematik eğitimine ilişkin yayınların incelendiği görülmektedir. Örneğin Kayhan ve Koca (2004), matematik eğitimi alanında 2000-2002 yılları arasında yapılan çalışmaları incelemişlerdir. Araştırmanın örneklemini, matematik eğitimi konulu CIJE (Current Index to Journals in Education) veri tabanındaki araştırma makaleleri ve Dissertation Abstract veri tabanındaki master ve doktora tezleri ile YÖK veri tabanındaki matematik eğitimi konulu tezler oluşturmaktadır. Bu çalışmanın bulgularına göre, 2000-2002 yıllarında en çok bilişsel boyut, matematik konuları (müfredat) ve öğretim yöntemleri alanlarında araştırma yapılmıştır. Tatar ve Tatar (2008), Türkiye'de yayınlanan fen bilimleri ve matematik eğitimi makalelerinin betimsel analizini yapmışlardır. 2000-2006 yılları arasında 26 hakemli dergide yayınlanmış toplam 680 makalenin anahtar kelimeleri incelenmiştir. Verilerin analizi sonucunda anahtar kelime olarak neredeyse cümle biçimindeki yapıların kullanıldığı görülmüştür. Fen ve matematik müfredatındaki konulara özgü anahtar kelimelerin nerdeyse tamamının frekansının düşük olduğu ilköğretim düzeyinde fen ve matematik müfredatı konularının ortaöğretim ve üniversite düzeyindeki konulara nazaran daha az ele alındığı, araştırmacıların fen eğitiminde kavram yanılgısı ve 
matematik eğitiminde ise tutum çalışmalarına daha çok ağırlık verdiği tespit edilmiştir. Ulutaş ve Ubuz (2008), 2000-2006 yılları arasında seçilen dört dergiden matematik eğitimi alanında yayınlanan toplam 129 makaleyi incelemişlerdir. Elde ettikleri bulgulara dayanarak yedi yılda matematik eğitiminde yapılan çalışmaların çoğunun örneklem bazında ilköğretim öğrencileri ve öğretmen adayları ile araştırma başlıkları bazında bilişsel, duyuşsal boyutlar ve öğretim yöntemleri konularında yapıldığını göstermiştir. Çalışmaların çoğunluğunun deneysel çalışmalar olduğu, nicel yöntemlerle, test ve anket kullanarak yapıldığı belirlenmiştir. Yayınlarda kullanılan konu başlıkları en fazla sayılar ve geometri konularında olurken, en fazla yayın bölge bazında İç Anadolu Bölgesi'ndeki üniversitelerin eğitim fakültesi mensuplarına aittir. Çiltaş, Güler ve Sözbilir (2012) çalışmalarında Türk araştırmacılar tarafından matematik eğitimi alanında yayınlanan makalelere ait bir içerik analizi gerçekleştirmişlerdir.1987-2009 yılları arasında uluslararası toplam 32 farklı dergide matematik eğitimi alanında yayınlanan toplam 359 makale incelenmiştir. Çalışma sonucunda 2002 yılından itibaren matematik eğitimi araştırmalarında büyük bir artışın olduğu, nicel çalışmaların daha çok tercih edildiği, araştırma konusu olarak öğrenme çalışmalarının ön planda olduğu, çalışmalarda tek veri toplama aracının daha çok kullanıldığı ve veri analiz yöntemi olarak yüzde ve frekans tablolarının kullanımının ön plana çıktığı tespit edilmiştir. Yapılan çalışmalar dikkate alındığında matematik eğitimi araştırmalarının süreklilik göstermediği, belirli zaman aralıklarıyla incelemelerin yapıldığı fakat ayrıntılı analizler içermediği görülmektedir. Yapılan çalışmalar, matematik eğitimi araştırmaları ile ilgili farklı çalışma önerileri sunmakta ve daha kapsamlı çalışmalar yapılması gerektiğini savunmaktadır.

$\mathrm{Bu}$ noktadan hareketle; yapılacak olan süreli yayın incelemeleri araştırmacılara, akademisyenlere ve makale çalışması yapmayı düşünen diğer kişilere süreli yayınlar hakkında veriler sunmaktadır. Böylece üzerinde daha çok durulması gereken alanlar daha belirgin hale gelmektedir. Bu çalışmada, 2009-2014 yılları arasında yayınlanan eğitim fakültesi dergileri ve ulakbim.gov.tr adresine kayıtlı dergiler incelenerek bir içerik analizi yapılmıştır. Ulaşılan makaleler; öğrenme alanları, makalenin konusu, araştırma yöntemleri, veri toplama araçları, örneklem, veri analiz yöntemi başlıklarında incelenmiştir. Ayrıca yazarların çalıştıkları kurumlar ve uzmanlık alanları da incelenmiş, disiplinler arası ve kurumlar arası çalışmalar tespit edilmeye çalışılmıştır. Söz konusu başlıklar belirlenirken bu araştırmanın amacıyla paralel doğrultuda gerçekleştirildiği düşünülen araştırmalardaki mevcut kriterler ve özellikle vurgulanmayan noktalar dikkate alınmıştır. Elde edilen verilerin, eğitim araştırmalarına yön vereceği, bununla birlikte araştırmacıların farklı perspektiften bakabilme becerilerine derinlik katacağı, yayın faaliyetlerinin geliştirilmesine de önemli katkılar sağlayacağı düşünülmektedir. Tüm bu amaçlara yönelik aşağıdaki sorulara cevap aranmıştır:

Türkiye'de;

1. Matematik eğitimi alanında 2009-2014 yılları arasında yapılan çalışmaların öğrenme alanlarına göre dağılışı nasıldır? 
2. Matematik eğitimi alanında 2009-2014 yılları arasında yapılan çalışmalar hangi konu alanlarında sıklık göstermektedir?

3. Matematik eğitimi alanında 2009-2014 yılları arasında yapılan çalışmalarda sıklıkla kullanılan araştırma yöntemleri nelerdir?

4. Matematik eğitimi alanında 2009-2014 yılları arasında yapılan çalışmalarda sıklıkla kullanılan veri toplama araçları nelerdir?

5. Matematik eğitimi alanında 2009-2014 yılları arasında yapılan çalışmalarda sıklıkla kullanılan örneklem ve örneklem büyüklüğü nasıldır?

6. Matematik eğitimi alanında 2009-2014 yılları arasında yapılan çalışmalarda sıklıkla kullanılan veri analiz yöntemleri nelerdir?

7. Matematik eğitimi alanında 2009-2014 yılları arasında yapılan çalışmalarda yazarların aynı üniversiteden olma sıklığı nedir?

8. Matematik eğitimi alanında 2009-2014 yılları arasında yapılan çalışmalarda yazarların disiplinler arası olma sıklığı nedir?

\section{Yöntem}

\section{Araştırma Deseni}

$\mathrm{Bu}$ araştırma nitel araştırma yöntem ve tekniklerine göre tasarlanmıştır. Nitel araştırma, sosyal yaşamı ve insanla ilgili problemleri kendine özgü metotlar aracılığıyla sorgulama ve anlamlandırma süreci olarak ifade edildiği (Creswell, 1998) gibi gözlem, görüşme ve doküman analizi gibi nitel veri toplama yöntemlerinin kullanıldığı, algıların ve olayların doğal ortamda gerçekçi ve bütüncül bir biçimde ortaya konmasına yönelik nitel bir sürecin izlendiği araştırma (Yıldırım ve Şimşek, 2013) olarak tanımlanabilir. Türkiye' de 2009-2014 yılları arasında matematik eğitimine yönelik gerçekleştirilen çalışmaların analiz edildiği bu araştırmada nitel araştırma desenlerinden durum çalışması deseni işe koşulmuştur. Araştırmada nitel araştırma deseni doğrultusunda verilerin toplanması doküman incelemesi yöntemi ile gerçekleştirilmiştir. Doküman incelemesi araştırılması hedeflenen olgu veya olgular hakkında bilgi içeren yazılı materyallerin analizini kapsar.

\section{Veri Toplama Yöntemi ve Aracı}

Çalışma kapsamına alınan makalelerin analizini yapmak için Sözbilir, Kutu ve Yaşar (2012) tarafından geliştirilen "Yayın Sınıflama Formu" kullanılmıştır. İlgili form eğitim bilimleri ve alt alanlarına ilişkin makaleleri tasnif etme amacıyla geliştirilmiş, bu araştırmada ise matematik eğitimi araştırmalarını tasnif için araştırmacılar tarafından revize edilerek kullanılmıştır. Matematik eğitimine yönelik yayın sınıflama formu, öğrenme alanı, konu alanı, araştırma yöntemi, veri toplama araçları, örneklem, veri analiz yöntemleri, yazarlar ve disiplin alanı şeklinde sekiz bölümden oluşmaktadır.

\section{Verilerin Analizi}


Araştırmada nitel araştırma deseni doğrultusunda veriler içerik analizi yöntemi ile analiz edilmiştir. İçerik analizi, belirli kurallara dayalı kodlamalarla bir metinin bazı sözcüklerinin daha küçük içerik kategorileri ile özetlendiği sistematik, yinelenebilir bir tekniktir (Büyüköztürk, Çakmak, Akgün, Karadeniz ve Demirel, 2012). İçerik analizinde temel amaç, toplanan verileri açıklayabilecek kavramalara ve ilişkilere ulaşmaktır. Betimsel analizde özetlenen ve yorumlanan veriler, içerik analizinde daha derin bir işleme tabi tutulur ve betimsel yaklaşımla fark edilemeyen kavram ve temalar bu analiz sonucu keşfedilebilir. İçerik analizinde temelde yapılan işlem, birbirine benzeyen verileri belirli kavramlar ve temalar çerçevesinde bir araya getirmek ve bunları okuyucunun anlayabileceği bir biçimde organize ederek yorumlamaktır (Yıldırım ve Şimşek, 2013). Verilerin analizinde, matematik eğitimi alanında uzmanlık (doktora) derecesine sahip iki araştırmacı görev almıştır. Araştırmacılar birbirinden bağımsız çalışarak belirlenen makaleleri önceden oluşturulan kriterler doğrultusunda analiz etmişlerdir. İlk kodlamalar sonucunda kodlayıcırlar arasındaki uyuşum yüzdesi Miles ve Huberman'ın (1994) formülüne göre \%78 olarak belirlenmiştir. Anlaşmazlığa neden olan maddeler üzerinde tekrar görüşülüp uygun kod konusunda fikir birliğine varılmıştır.

2009-2014 yılları arasında ULAKBIM ulusal veri tabanında indekslenen ve eğitim fakültelerince yayımlanan dergiler incelenmiştir. Araştırma amacı bağlamında belirlenen dergilerde yer alan 284 makale tasnif edilerek sekiz temel kategori altında analiz edilmiştir. Analiz edilen makalelerin belirlenen kategorilere göre tekrarlanma sıklıkları ve yüzdeleri hesaplanarak bunlar üzerine tartışmalar gerçekleştirilmiştir.

\section{Bulgular ve Yorum}

Araştırmanın bu bölümünde, belirlenen dergilerde yayınlanan makalelerin farklı değişkenler açısından yapılan analizleri ve elde edilen bulgular yer almaktadır. $\mathrm{Bu}$ bağlamda sırasıyla; öğrenme alanları, konu alanları, araştırma yöntemleri, veri toplama araçları, örneklem, veri analizi, yazar dağılımı (üniversitelere göre) ve disiplinler arası olma açısından araştırma bulgularına bu bölümde yer verilmiştir. Araştırma bulguları, frekans ve yüzdelik sonuçları şeklinde tablolaştırılmış ve tablo yorumları yapılmıştır.

$\mathrm{Bu}$ kapsamda ilk olarak araştırma kapsamında analiz edilen çalışmaların öğrenme alanlarına ilişkin dağılımlarına bakılarak elde edilen bulgular tablo 1'de gösterilmiştir. 
Tablo 1. İçerik analizine tabi tutulan araştırmaların öğrenme alanlarına göre dağılımı

\begin{tabular}{lc}
\hline \multicolumn{1}{c}{ Öğrenme Alanları } & $\%$ \\
\hline Sayılar ve işlemler & 14 \\
Cebir & 5 \\
Geometri ve ölçme & 16 \\
Veri analizi & 4 \\
Olasılık & 2 \\
Analiz & 6 \\
Diğer & 9 \\
Belirli bir öğrenme alanı hedeflemeyen & 43 \\
\hline
\end{tabular}

Tablo 1' e göre çalışmaların yarıya yakınının (\%43) herhangi bir matematik öğrenme alanını konu edinmediği görülmektedir. Matematik öğrenme alanlarını ele alan makalelere bakıldığında geometri ve ölçme (\%16) ile sayılar ve işlemler (\%14) öğrenme alanlarının ilk sıralarda yer aldığı görülmektedir. Buna karşın olasılık, veri analizi, cebir ve analiz öğrenme alanlarıyla ilgili çalışmaların temsil oranlarının düşük olduğu (sırasıyla \%2, \%4, \%5, \%6) ortaya çıkmıştır.

Tablo 2'de 2009-2014 yılları arasında Türkiye'de matematik eğitimi alanında yapılan makale çalışmalarının konusuna göre dağılımı verilmektedir.

Tablo 2. İçerik analizine tabi tutulan araştırmaların konu alanlarına göre dağılımı

\begin{tabular}{ll}
\hline Makalenin Konusu & $\%$ \\
\hline Öğretmen yetiştirme & 22 \\
Müfredat, ölçme ve değerlendirme & 18 \\
Öğrenme bağlamı (öğrenme ortamı, öğrenci karakteristikleri) & 14 \\
Öğretme & 12 \\
Kültürel, sosyal ve cinsiyet ile ilgili durumlar & 12 \\
Kavram öğrenme & 11 \\
Eğitim teknolojileri & 8 \\
Tarih, felsefe, epistemoloji ve matematiğin doğası & 3 \\
Formal olmayan öğrenme & 1
\end{tabular}

Tablo 2' de belirgin bir farklılık olmamakla birlikte matematik eğitimi çalışmalarında en fazla öğretmen yetiştirme (\%22) ve müfredat, ölçme ve değerlendirme (\%18) konularının tercih edildiği görülmektedir. Öğrenme bağlamı, kültürel, sosyal ve cinsiyet ile ilgili durumlar, kavram öğrenme, eğitim teknolojileri konularına ise çalışmalarda yaklaşık oranlarda (\%8 ile \%14 arasında değişen) yer verilmiş olduğu görülmektedir. Buna karşın tarih, felsefe, epistemoloji ve matematiğin doğası ve formal olmayan öğrenme konularına makalelerde düşük oranda (sırasıyla \%3 ve \%1) yer verildiği anlaşılmaktadır. 
Araştırmanın üçüncü alt probleminde ise örnekleme alınan matematik eğitimi alanındaki makalelerde işe koşulan araştırma yöntemleri ele alınmış bu kapsamda ulaşılan bulgular tablo 3' te gösterilmiştir.

Tablo 3. İçerik analizine tabi tutulan araştırmaların araştırma yöntemlerine göre dağılımı

\begin{tabular}{|c|c|c|}
\hline Doğası & Yöntemler & $\%$ \\
\hline \multirow{2}{*}{ Deneysel } & & \multirow[t]{2}{*}{10} \\
\hline & Zayıf deneysel & \\
\hline \multirow{5}{*}{ Deneysel Olmayan } & Tarama & \multirow{5}{*}{5} \\
\hline & Betimsel & \\
\hline & Karşılaştırmalı & \\
\hline & İkincil veri analizi & \\
\hline & Korelasyonel & \\
\hline \multirow{3}{*}{ Etkileşimli } & Örnek olay & \multirow{3}{*}{20} \\
\hline & Olgu bilim & \\
\hline & Diğer & \\
\hline \multirow{5}{*}{ Etkileşimsiz } & İçerik/doküman analizi & \multirow{5}{*}{5} \\
\hline & Derleme & \\
\hline & Tarihsel analiz & \\
\hline & Meta analiz & \\
\hline & Diğer & \\
\hline \multirow{3}{*}{ Karma } & Açıklayıcı & \multirow{3}{*}{7} \\
\hline & Çeşitleme & \\
\hline & Keşfedici & \\
\hline
\end{tabular}

Tablo 3 incelendiğinde çalışmaların yarısından fazlasında (\%57) deneysel olmayan yöntemlerin kullanıldığı belirlenmiştir. Etkileşimli doğaya sahip çalışmalar (\%20) ikinci sıradadır. İlgili yıllarda deneysel, karma ve etkileşimsiz yöntemlerin kullanıldığı çalışmaların ise düşük oranlarda (sırasıyla \%10, \%7, \%5) olduğu tablo 3' ten görülmektedir. Çalışmaların yöntemlerine bakıldığında, yapılan deneysel çalışmaların tamamına yakınının yarı deneysel olduğu, deneysel olmayan 
çalışmalarda ise betimsel ve tarama yöntemlerinin diğer yöntemlere göre daha fazla kullanıldığı görülmektedir. Diğer taraftan etkileşimli doğaya sahip çalışmaların büyük bir çoğunluğu örnek olay çalışmasıdır. Buna ek olarak etkileşimsiz doğaya sahip çalışmalarda içerik /doküman analizi, karma yöntemlerden ise açıklayıcı, çeşitleme yöntemler daha çok tercih edilenlerdir.

Tablo 4'te ilgili yıllarda Türkiye'de matematik eğitimi alanında yapılan makale çalışmalarının veri toplama araçlarına göre dağılımı verilmiştir.

Tablo 4. İçerik analizine tabi tutulan araştırmaların veri toplama araçlarına göre dağılımı

\begin{tabular}{ll}
\hline Veri toplama araçları & $\%$ \\
\hline Başarı testi & 22 \\
Görüşme (mülakat) formları & 21 \\
Anket & 17 \\
Dokümanlar & 10 \\
Algı/ilgi/tutum/yetenek/kişilik vb. testler & 9 \\
Ölçekler & 8 \\
Diğer & 7 \\
Alternatif değerlendirme araçları & 4 \\
Gözlem & 2 \\
\hline
\end{tabular}

Tablo 4' ten de görüldüğü üzere çalışmalarda veri toplama aracı olarak en çok tercih edilenlerin sırasıyla başarı testi (\%22), görüşme formları (\%21) ve anketler (\%17) olduğu görülmektedir. Buna karşın alternatif değerlendirme araçları (\%4) ve gözlemler (\%2) oldukça az çalışmada veri toplama aracı olarak seçilmiştir. Dokümanlar, algı/ilgi/tutum/yetenek/kişilik ve benzeri testler, ölçekler ise \%8 - \%10 aralığında değişen oranlarda matematik eğitimi çalışmalarında kullanılmıştır. Bu sonuç ise en çok öne çıkan araştırma yöntemleriyle (tarama, betimsel, örnek olay ve yarı deneysel) bu yöntemlerde kullanılabilecek olası veri toplama araçları bakımından paralellik göstermektedir.

Araştırmanın beşinci alt probleminde analiz edilen çalışmalarda ele alınan örneklem türlerine ilişkin dağılımlar tablo 5 ’te gösterilmiştir. 
Tablo 5. İçerik analizine tabi tutulan araştırmaların ele alınan örneklem türüne göre dağılımı

\begin{tabular}{ll}
\hline Örneklem Türü & $\%$ \\
\hline Lisans & 35 \\
Ortaokul & 25 \\
Öğretmen & 15 \\
Lise & 12 \\
İlkokul & 7 \\
Okul Öncesi & 2 \\
Veliler & 1 \\
Lisansüstü & 1 \\
Diğer & 1 \\
Yöneticiler & 1 \\
\hline
\end{tabular}

Tablo 5' te yer alan veriler analiz edildiğinde, matematik eğitimi çalışmalarında örneklem olarak sıklıkla, lisans (\%35) ve ortaokul (\%25) öğrencilerine yer verildiği görülmektedir. Bunu öğretmenler (\%15), lise öğrencileri (\%12) ve ilkokul öğrencileri (\%7) takip etmektedir. Örneklem olarak okul öncesi öğrencileri, velileri, lisansüstü öğrencileri, yöneticileri ve diğer kişileri seçen çalışmaların çok düşük oranlarda (her biri \%1) olması dikkat çekmektedir.

Tablo 6' da matematik eğitimi alanında yapılan çalışmalarının örneklem büyüklüklerine göre dağılımı verilmiştir.

Tablo 6. İçerik analizine tabi tutulan araştırmaların örneklem büyüklüğüne göre dağılımı

\begin{tabular}{ll}
\hline Örneklem Büyüklüğü & $\%$ \\
\hline $101-300$ arası & 26 \\
$31-100$ arası & 26 \\
$301-1000$ arası & 17 \\
$11-30$ arası & 13 \\
Belirtilmemiş & 8 \\
$1-10$ arası & 7 \\
1000 'den fazla & 3
\end{tabular}

Tablo 6' ya göre en fazla tercih edilen örneklem büyüklüklerinin 31-100 (\%26) ve 101-300 (\%26) kişilik olduğu anlaşılmaktadır. Bu örneklemleri 301-1000 arası ve 11-30 katılımcının içerildiği çalışmalar (sırasıyla \%17 ve \%13' lük oranlarla) takip etmektedir. Yine örneklem seçiminde çok küçük veya çok büyük örneklemlerden kaçınıldığı görülmektedir. 1-10 arası ve 1000 den fazla kişiyle sürdürülen çalışmalar tüm çalışmaların çok az bir kısmını (sırasıyla \%7, \%3) oluşturmaktadır. 
Tablo 7'de 2009-2014 yılları arasında Türkiye'de matematik eğitimi alanında yapılan makale çalışmalarının veri analiz yöntemlerine göre dağılımı sunulmuştur.

Tablo 7. İçerik analizine tabi tutulan araştırmaların veri analiz yöntemlerine göre dağılımı

\begin{tabular}{ll}
\hline Veri Analiz Yöntemi & $\%$ \\
\hline Nicel & 40 \\
Nitel & 45 \\
Karma & 8 \\
Yok & 7
\end{tabular}

Tablo 7 incelendiğinde çalışmaların veri analizinde en fazla nicel (\%40) ve nitel (\%45) yöntemlerin kullanıldığı, çok düşük oranda da karma (\%8) yöntemin kullanıldığı ortaya çıkmıştır.

İlgili yıllardaki matematik eğitimi çalışmalarında yer alan paydaşların çalıştıkları kurumlara ilişkin dağılım tablo 8' de sunulmuştur.

Tablo 8. İçerik analizine tabi tutulan araştırmalardaki yazarların kurumlara göre dağılımı

\begin{tabular}{ll}
\hline Yazar Ortaklıkları & $\%$ \\
\hline Aynı Üniversiteden & 38 \\
Farkı Üniversiteden & 26 \\
Üniversite Dışı Yazarla & 12 \\
Tek yazar & 20 \\
Karma & 5 \\
\hline Toplam & $\mathbf{1 0 0}$ \\
\hline
\end{tabular}

Tablo 8' de matematik eğitiminde yapılan çalışmalar arasında en fazla aynı üniversiteden olan yazarların yaptığı çalışmalar (\%38) öne çıkmaktadır. Farklı üniversitelerde çalışan araştırmacıların yaptığı çalışımlalar tüm çalışmaların \%26' sını oluşturmakta iken tek yazarlı çalışmalar \%20'sini kapsamaktadır. Bunun yanı sıra bir üniversitedeki araştırmacının üniversite dışı kurumlardaki araştırmacılarla (MEB v.b.) yaptıkları çalışmalar \%12'lik bir orana denk gelmektedir. Diğer taraftan, farklı üniversitedeki yazarların farklı bir kurumdaki yazar(lar)la yaptıkları çalışmalar ise en düşük dağılıma sahip olmakla birlikte bu oran \%5'tir.

Araştırmanın son alt probleminde ise analiz edilen araştırmaları gerçekleştiren yazarların uzmanlık alanlarına göre etkileşimleri incelenmiş ve bununla ilgili dağılımlara tablo 9' da yer verilmiştir. 
Tablo 9. İçerik analizine tabi tutulan araştırmalardaki yazarların uzmanlık alanlarına göre etkileşimlerinin yüzdesel dağılımı

\begin{tabular}{ll}
\hline Uzmanlık alanları arası etkileşim & $\%$ \\
\hline Matematik eğitimi & 67,3 \\
Eğitim bilimleri & 7,4 \\
Matematik eğitimi-eğitim bilimleri & 6,7 \\
Matematik eğitimi-diğer alanlar & 5,6 \\
Matematik eğitimi-fen eğitimi & 3,2 \\
Diğer alanlar & 3,2 \\
Matematik eğitimi-bilgisayar ve öğretim teknolojileri & 2,1 \\
Fen eğitimi & 1,4 \\
Eğitim bilimleri-diğer alanlar & 1,1 \\
Matematik eğitimi-eğitim bilimleri-diğer alanlar & 0,7 \\
Bilgisayar ve öğretim teknolojileri-eğitim bilimleri & 0,6 \\
Matematik eğitimi-fen eğitimi-diğer alanlar & 0,4 \\
Matematik eğitimi-fen eğitimi-bilgisayar ve öğretim teknolojileri & 0,3 \\
\hline Toplam & $\mathbf{1 0 0}$ \\
\hline
\end{tabular}

Tablo 9' da yer alan veriler incelendiğinde analiz edilen araştırmalarda yer alan yazarların çoğunlukla matematik eğitimi alanında uzman oldukları $(\% 67,3)$ ve farklı alanlardaki uzmanlarla çalışmayı tercih etmedikleri görülmüştür. İkinci sırada ise eğitim bilimleri alanında uzmanlığı olan araştırmacıların bireysel ya da yine eğitim bilimleri alanında uzmanlarla $(\% 7,4)$ matematik eğitimi çalışmalarını yürüttükleri görülmektedir. Benzer şekilde \%1,4 oranında fen eğitimi uzmanlarının matematik eğitimi uzmanları olmadan matematik eğitimine yönelik araştırmalar gerçekleştirdikleri görülmektedir. Disiplinler arası bağlantıya bakıldığında ise matematik eğitimi alanında uzmanların farklı alanlardaki uzmanlarla gerçekleştirdikleri matematik eğitimi araştırmalarında en fazla eğitim bilimleri alanındaki uzmanlarla $(\% 6,7)$ bu çalışmaları organize ettikleri görülmektedir. Matematik eğitimi ile fen eğitimi uzmanlarının beraber gerçekleştirdikleri araştırmaların ise \%3,2 civarında olduğu görülmüştür.

\section{Tartışma ve Sonuç}

Bu araştırmada, Türkiye`de 2009-2014 yılları arasında "Matematik Eğitimi" alanında yayınlanmış makalelerin öğrenme alanları, konu alanları, araştırma yöntemleri, veri toplama araçları, örneklem, veri analizi, yazar dağılımı (üniversitelere göre) ve disiplinler arası olma açısından değerlendirilmesi ve matematik eğitimi alanındaki araştırma eğilimlerinin belirlenmesi amaçlanmıştır. 
Araştırma kapsamında örneklemi oluşturan çalışmaların ilk olarak öğrenme alanlarına göre dağılımları incelenmiştir. Ulaşılan sonuçlar göstermektedir ki matematik eğitimi temelli araştırmaların çoğunda herhangi bir öğrenme alanı hedefe alınmamıştır. Bununla birlikte öğrenme alanlarının hedef olarak belirtildiği çalışmalarda ise sayılar ve işlemler öğrenme alanı ile geometri ve ölçme öğrenme alanlarının ön plana çıktığı görülmüştür. Benzer şekilde Ulutaş ve Ubuz (2008) matematik eğitiminde araştırmalar ve eğilimleri analiz ettikleri araştırmalarında matematiksel konu bazındaki dağılımı incelemişler ve çalışmaların sayılar ve geometri konularında yoğunlaştığını, bunun dışındaki konularda yapılmış olan çalışmalar oldukça yetersiz olduğunu belirtmişlerdir. Bu araştırmanın öğrenme alanları başlığında ulaşılan sonuçların Çiltaş, Güler ve Sözbilir' in (2012) çalışmasıyla farklılıklar taşıdığı görülmektedir. Çiltaş, Güler ve Sözbilir' in (2012) çalışmalarında konu bazlı çalışmaların daha az olduğu ve özellikle geometri konusunda ise çok az sayıda araştırma yapıldığını ifade etmişlerdir. Bu çalışmada öğrenme alanlarına yönelik elde edilen sonuçlardan bir diğeri de araştırmalarda en az hedeflenen öğrenme alanlarının olasılık ve veri analizi olduğudur.

Araştırmanın ikinci alt probleminde öğrenme alanlarına göre yapılan analizin ardından biraz daha detaya inilerek 2009-2014 yılları arasında ülkemizde matematik eğitimiyle ilgili yapılan çalışmaların konu alanına göre dağılımının nası olduğu sorusuna cevap aranmaya çalışılmıştır. Burada ise araştırmaların en fazla öğretmen yetiştirme konu alanında gerçekleştirildiği görülmüştür. Söz konusu sonucun Çiltaş, Güler ve Sözbilir (2012) tarafından gerçekleştirilen araştırmanın sonuçlarıyla oldukça tutarlı olduğu söylenebilir. Örnek verilen araştırmanın analiz sonuçlarına göre, matematik eğitiminde en sık araştırılan konular arasında öğrenme, öğretme ve öğretmen eğitiminin yer aldığı belirlenmiştir. Bu sonuç Lubiensky ve Bowen (2000) tarafından yapılan araştırma bulgularını destekler niteliktedir. Matematik eğitimi alanında gerçekleştirilen araştırmalarda konu alanı olarak öğretmen yetiştirme başlığının ön plana çıkmasındaki temel faktörün yazarların çoğunlukla üniversitelerde görev yapmasından dolayı öğretmen adaylarına yönelik araştırmalara öncelik vermesinden kaynaklandığı düşünülebilir. Bununla birlikte konu alanlarına göre en az değinilen başlıkların ise matematik tarihi, felsefesi, epistemolojisi, matematiğin doğası ve formal olmayan öğrenme olduğu görülmüştür.

İçerik analizine tabi tutulan araştırmalarda işe koşulan araştırma yöntemlerinin dağılımına bakıldığında ise genel eğilimin deneysel olmayan araştırmaların gerçekleştirilmesi yönünde olduğu görülmüştür. Araştırmanın doğası kapsamında deneysel olmayan çalışmalardan sonra en fazla etkileşimli çalışmalara ağırlık verilmiştir. Bahsedildiği gibi deneysel olmayan doğada gerçekleştirilen araştırmalarda daha çok ön plana çıkan yöntemler betimsel ve tarama yöntemleri olurken etkileşimli araştırmalarda örnek olay yönteminin fazlaca kullanıldığı görülmüştür. Ulaşılan bu sonucun hem yerli hem de yabancı literatürle paralellik gösterdiği söylenebilir. Örneğin Çiltaş, Güler ve Sözbilir (2012) araştırmalarında nicel yöntemlerin $(\% 59,6)$ daha çok kullanıldığını, bunu nitel yöntemlerin $(\% 35,1)$ takip ettiğini, karma 
araştırmaların ise çok az olduğunu ifade etmişlerdir. Ulutaş ve Ubuz (2008) da benzer şekilde yayınlanan araştırmaların çoğunluğunun nicel çalışmalar olduğunu belirlemiştir. Nitel çalışmaların bazı yıllarda genel olarak artma kararlılığı göstermiş olmasına rağmen nicel çalışmalarla kıyaslandığında oldukça sınırlı sayıda kaldığı ifade edilmiştir. Hart, Smith, Swars \& Smith (2009) ise ülkemizde gerçekleştirilen araştırmalarla yabancı araştırmalar arasındaki temel farkı ortaya koyabilecek bir sonuca ulaşmışlardır. Adı geçen araştırmacılar 2005 yılına kadar gerçekleştirilen araştırmalardaki yöntemleri incelemişler ve araştırmaların yaklaşık yarısının nitel araştırma deseni üzerine inşa edildiğini ifade etmişlerdir. Araştırmada dikkat çeken bir diğer nokta da nitel araştırmalardan sonra en çok işe koşulan araştırma deseninin nicel değil karma desenler olduğudur. Yani ülkemizdeki araştırmaların aksine yabancı literatürde nitel ve karma desene daha önem verilirken ülkemizdeki çalışmalarda daha çok nicel paradigma temelli yöntemlerin işe koşulduğu görülmektedir.

Matematik eğitimine yönelik gerçekleştirilen çalışmaların yöntem kısımlarına yönelik analizlerde veri toplama araçları da incelenmiş ve elde edilen sonuçlara göre başarı testleri diğer ölçme araçlarına kıyasla daha çok kullanılmıştır. Başarı testlerinin yanı sıra görüşme (mülakat) formları ile değişik alanlardaki ölçekler başlıca veri toplama aracı olarak çalışmalarda sıklıkla kullanılmıştır. Başarı testlerinin ve anketlerin ilk üç sırada olması nicel çalışmalara ağırlık verilmesinin bir sonucu olarak karşımıza çıkmaktayken nitel araştırmalarda ise daha çok görüşme formlarının kullanıldığı sonucuna ulaşılmaktadır. Buna karşıık matematik eğitimine yönelik araştırmalarda alternatif değerlendirme araçlarının ve gözlem faaliyetlerinin yeterince işe koşulmadığı sonucuna ulaşılmıştır.

Analiz edilen çalışmalarda ele alınan örneklem hem tür olarak hem de büyüklük olarak ele alınarak incelenmiştir. Öncelikle içerik analizine tabi tutulan araştırmaların örneklem türüne göre dağılımına bakılmış ve çalışmaların belirgin bir şekilde lisans öğrencileri üzerine gerçekleştirildiği sonucuna ulaşılmıştır. Diğer bir ifadeyle öğretmen-öğretmen adayı kıyaslaması yapılacak olursa çalışmalarda örneklem grubu olarak öğretmenlerden ziyade öğretmen adayları tercih edilmiştir. Okul öncesi, ilkokul, ortaokul ve lise düzeyi karşılaştırıldığında ise yoğunluğun ortaokul öğrencilerinde olduğu görülmektedir. Hatta ortaokul öğrencilerinin örneklem olarak ele alındığı çalışmalar öğretmenlerin örneklem olarak ele alındığı çalışmalardan daha fazladır. Yurtdışında gerçekleştirilen çalışmalara bakıldığında eğitim kademelerine göre en fazla yoğunluğun ilkokul kademesinde olduğu görülmektedir (Lubiensky ve Bowen, 2000). Veliler, yöneticiler ve lisansüstü öğrencileriyle yürütülen araştırmaların oldukça kısıtlı olduğu görülmüştür. Daha önce de ifade edildiği gibi öğretim elemanlarının kolay ulaşılabilir durumlarından dolayı araştırmalarını özellikle lisans öğrencileri üzerinden gerçekleştirdikleri söylenebilir. Analiz edilen çalışmalardaki örneklem büyüklüklerine bakıldığında ise çalışmaların 31-100 ile 101-300 arası örneklem sayılarında gerçekleştirildiği görülmüştür. Söz konusu sonuçların Tatar ve Tatar (2006), Ulutaş ve Ubuz (2008) ve Çiltaş, Güler ve Sözbilir (2012) tarafından gerçekleştirilen çalışmaların sonuçlarıyla paralellik 
gösterdiği söylenebilir. Özellikle nicel araştırmaların nitel araştırmalara kıyasla daha fazla gerçekleştirilmesi, araştırmacıları 100 kişilik örneklemlerin üzerine çıkılması konusunda zorlamıştır. 1000 kişiden fazla örneklemli çalışmalara diğerlerine kıyasla daha az rastlanmıştır. Dikkat çekici bir diğer sonuç ise bazı araştırmalarda örneklem sayısının belirtilmemiş olmasıdır. Sonuçlara bakıldığında nitel desende gerçekleştirilen araştırmaları çoğunlukla 11-30 kişilik örneklemler üzerinde gerçekleştirildiği, yarı yapılandırımış anket formlarının kullanıldığı bazı araştırmalarda ise nadiren 31-100 kişilik örneklemlere ulaşıldığı görülmüştür.

Matematik eğitimine yönelik araştırmaların analiz edilmesinde yöntem odaklı analizlerde son olarak çalışmalarda kullanılan veri analiz yöntemlerinin dağılımı incelenmiştir. Matematik eğitimcileri, yayınlarının büyük bir kısmında tek veri analiz yöntemi kullanmışlardır. Bununla birlikte araştırmacıların küçük bir kısmında iki veri analiz yöntemi kullanmışlardır. Nitel ve nicel veri analiz yöntemlerinin oransal olarak birbirine yakın olduğu sonucuna ulaşılmıştır. Bununla beraber araştırma desenlerinde olduğu gibi veri analiz yöntemlerinde de tekli yöntemlerin tercih edilmesi karma yöntemlerin kullandığı araştırmalara göre geçerlik ve güvenirlik açısından yetersiz kalabilmektedir. Veri analiz yöntemlerinde dikkat çekici bir diğer sonuç ise araştırmaların bir kısmında ne tür veri analiz yöntemlerinin işe koşulduğu hakkında herhangi bir açıklamanın yer almayışıdır.

Araştırmanın bir sonraki aşamasında içerik analizine tabi tutulan araştırmalardaki yazarların kurumlara göre dağılımı incelenmiştir. Araştırma sonuçlarına göre araştırmalar çoğunlukla tek yazar tarafından değil birden çok yazar tarafından işbirliği içerisinde gerçekleştirilmiştir. Söz konusu çalışmalardaki yazarların dağıımına bakıldığında ise aynı üniversitede yer alan yazarlara tarafından ortaya konulan çalışmaların ağırlıklı olduğu görülmüştür. Birden fazla yazarla gerçekleştirilen çalışmaların olaylara ve eğilimlere farklı açılardan yaklaşabilme adına önemli olduğu düşünülmektedir. Ancak buna ilaveten farklı üniversite ya da kurumlarda çalışmakta olan kişilerle gerçekleştirilen çalışmaların alana daha fazla katkı getirebileceği söylenebilir. Örneğin üniversite düzeyinde yani lisans seviyesinde gerçekleştirilen araştırmalarda yazarların farklı üniversitelerde olması hem örneklem açısından araştırmaya zenginlik katabilir hem de üniversitelere göre farklı uygulamaların bir zenginlik unsuru olarak ele alınıp değerlendirilmesini sağlayabilir. Buna ilave olarak yine ilkokul seviyesinde gerçekleştirilen çalışmada yazarlardan birinin sınıf öğretmeni olması ya da ortaokul ya da lise seviyesinde gerçekleştirilen çalışmalarda bu seviyelerde görev yapan öğretmenlerin yer alması "işin mutfağından gelme" tabirine iyi bir örnek olacaktır ve araştırmaya farklı açılardan bakabilme ve değerlendirme açısından olumlu katkıları olacaktır.

Araştırmada son olarak içerik analizine tabi tutulan araştırmalardaki yazarların uzmanlık alanlarına göre etkileşimleri incelenmiştir. Araştırma sonuçları göstermektedir ki birden fazla yazarın yer aldığı matematik eğitimi araştırmalarında yazarların büyük çoğunluğunun sadece matematik eğitimi alanında çalışmalar 
gerçekleştirmektedir. Diğer bir ifadeyle çalışmaların büyük bir çoğunluğu sadece matematik alanına yönelik gerçekleştirilip disiplinler arası olma durumu gözetilmemiştir. Bununla beraber farklı disiplinleri ilişkilendiren araştırmalar da tespit edilmiş ve bunların, yazarların alanlara göre dağılımları incelendiğinde matematikle birlikte yazarların en yoğun çalıştıkları alanın eğitim bilimleri olduğu sonucuna ulaşılmıştır. Eğitim bilimlerinin yanı sıra yazarların fen eğitimi ve bunun ardından da bilgisayar ve öğretim teknolojileri alanlarında çalışmalar yürüttükleri görülmüştür.

Türkiye'de matematik eğitimi araştırmalarının durumunun ve mevcut eğilimin belirlenmesi amacıyla gerçekleştirilen bu araştırmanın bu alanda araştırmalar gerçekleştirme arzusu içinde bulunan kişilere yol gösterici olması açısından da oldukça önemli olduğu düşünülmektedir. Söz konusu araştırma öğrenme alanı, konu alanı gibi ana başlıklara yer vererek yukarıda ifade edildiği gibi araştırmacılara üzerinde durulması gereken alanlar hakkında bilgi vermekte bunun yanı sıra yöntem başlığı altında gözden kaçıılan ya da eksik bırakılan noktalara vurgu yaparak bundan sonra gerçekleştirilecek olan matematik eğitimi araştırmalarının daha kaliteli olarak gerçekleştirilmesine yardımcı olacaktır. Bunun yanı sıra benzer çalışmaların belirli aralıklarla gerçekleştirilerek rutin hale getirilmesi ve içeriğinin yüksek lisans tezlerinin de katılımıyla genişletilmesi önerilmektedir.

\section{Kaynaklar}

Aksu, H. H. (2008). Öğretmen adaylarının matematik öğretimine yönelik öz-yeterlilik inançları. Abant Izzet Baysal Üniversitesi Eğitim Fakültesi Dergisi.

Apaydın, S. (2009). 2000-2008 yılları arasında Türkiye'de fizik eğitimi araştırmaları. I. Uluslararası Türkiye Eğitim Araştırmaları Kongresi, Çanakkale Onsekiz Mart Üniversitesi, Antalya.

Arık, R. S., \& Türkmen, M. (2009). Eğitim bilimleri alanında yayımlanan bilimsel dergilerde yer alan makalelerin incelenmesi. I. Uluslararası Türkiye Eğitim Araştırmaları Kongresi.

Aydın, B. (2003). Bilgi toplumu oluşumunda bireylerin yetiştirilmesi ve matematik öğretimi. Pamukkale Üniversitesi Eğitim Fakültesi Dergisi, 2(14), 183-190.

Büyüköztürk, S., Kılıç Çakmak, E., Akgün, O. E., Karadeniz, S., \& Demirel, F. (2012). Bilimsel araştırma yöntemleri. Ankara: Pegem Akademi.

Cohen, L., Manion, L. \& Morrison, K., (2007). Research methods in education. RoutledgeFalmer, London.

Creswell, J.W., (1998). Qualitative inquiry and research design: Choosing among five traditions. Thousand Oaks, CA: Sage Pub.

Çoban, A. (2002). Matematik Dersinin İlköğretim Programları ve Liselere Giriş Sınavları Açısından Değerlendirilmesi. V. Ulusal Fen Bilimleri ve Matematik 
Eğitimi Kongresi. (16-18 Eylül 2002). Ankara: ODTÜ Kültür ve Kongre Merkezi.

Gün, Z. \& Erdem, Z. (2014). Uyum analizi yöntemiyle matematik başarısını etkileyen faktörlerin incelenmesi. Adıyaman Üniversitesi Eğitim Bilimleri Dergisi, 4(2), 98-118.

Hart, L. C., Smith, S. Z., Swars, S. L., \& Smith, M. E. (2009). An examination of research methods in mathematics education: 1995- 2005. Journal of Mixed Methods Research, 3 (1) 26-41.

Kayhan, M., \& Özgün-Koca, S. A. (2004). Matematik eğitiminde araştırma konuları: 2000-2002. Hacettepe Üniversitesi Eğitim Fakültesi Dergisi, 26(26), 72-81.

Lubienski, S.T. \& Bowen, A. (2000). Who's counting? A Survey of Mathematics Education Research 1982-1998. Journal for Research in Mathematics Education. 31(5), 626-633.

Miles, M. B., \& Huberman, A. M. (1994). Qualitative data analysis: A sourcebook. Beverly Hills: Sage Publications.

Selçuk, Z., Palancı, M., Kandemir, M., \& Dündar, H. (2014). Eğitim ve bilim dergisinde yayınlanan araştırmaların eğilimleri: İçerik analizi. Eğitim ve Bilim, 39(173).

Sözbilir, M., Güler, G., \& Çiltaş, A. (2012). Türkiye'de matematik eğitimi araştırmaları: Bir içerik analizi çalışması. Kuram ve Uygulamada Eğitim Bilimleri, 12, 565580.

Sözbilir, M., Kutu, H., \& Yaşar, M. D. (2012). Science education research in Turkey: A content analysis of selected features of papers published. In J. Dillon\& D. Jorde (Eds). The World of Science Education: Handbook of Research in Europe (pp.341-374). Rotterdam: Sense Publishers.

Tatar, E., \& Tatar, E. (2008). Fen bilimleri ve matematik eğitimi araştırmalarının analizi I: Anahtar kelimeler. Inönü Üniversitesi Eğitim Fakültesi Dergisi, 9 (16).

Ulutaş, F., \& Ubuz, B. (2008). Matematik eğitiminde araştırmalar ve eğilimler: 2000 ile 2006 yılları arası. İlköğretim Online, 7(3).

Yıldırım, A. \& Şimşek, H. (2013). Sosyal bilimlerde nitel araştırma yöntemleri. (9. Baskı). Ankara: Seçkin Yayıncılık. 